\title{
Pharmacokinetic and pharmacodynamic effects of comedication of clopidogrel and dabigatran etexilate in healthy male volunteers
}

\author{
Sebastian Härtter • Regina Sennewald • \\ Cornelia Schepers • Sybille Baumann • Holger Fritsch • \\ Jeffrey Friedman
}

Received: 31 January 2012 / Accepted: 28 April 2012 /Published online: 11 July 2012

(C) The Author(s) 2012. This article is published with open access at Springerlink.com

\begin{abstract}
Purpose To evaluate the pharmacokinetic and pharmacodynamic effects of concomitant administration of single loading doses of clopidogrel or multiple doses of clopidogrel with multiple doses of dabigatran etexilate.

Methods This was an open-label trial in healthy male subjects. In part 1 (pilot, $n=8)$ and part $3(n=12)$, a single dose of clopidogrel (300 or $600 \mathrm{mg}$, respectively) was given concomitantly with dabigatran etexilate at steady state; part
\end{abstract}

Electronic supplementary material The online version of this article (doi:10.1007/s00228-012-1304-8) contains supplementary material, which is available to authorized users.

\author{
S. Härtter $(\triangle) \cdot$ R. Sennewald $\cdot$ H. Fritsch \\ Boehringer Ingelheim Pharma GmbH \& Co. KG, \\ Translational Medicine, \\ Biberach an der Riss, Germany \\ e-mail: Sebastian.haertter@boehringer-ingelheim.com \\ R. Sennewald \\ e-mail: Regina.Sennewald@boehringer-ingelheim.com \\ H. Fritsch \\ e-mail: Holger.Fritsch@boehringer-ingelheim.com \\ C. Schepers \\ Boehringer Ingelheim Pharma GmbH \& Co. KG, \\ Medical Data Services, \\ Ingelheim am Rhein, Germany \\ e-mail: Cornelia.Schepers@boehringer-ingelheim.com \\ S. Baumann \\ CRS, Clinical Research Services Mannheim GmbH, \\ Mannheim, Germany \\ e-mail: Sybille.Baumann@crs-group.de \\ J. Friedman \\ Boehringer Ingelheim Pharmaceuticals Inc, \\ Ridgefield, CT, USA \\ e-mail: jeffrey.friedman@boehringer-ingelheim.com
}

2 was a randomized, multiple-dose, crossover study with the test treatment being clopidogrel at steady state $[300 \mathrm{mg}$ loading dose on day 1 , then $75 \mathrm{mg}$ once daily (qd)] with concomitant dabigatran.

Results Bioavailability was moderately increased when a loading dose of clopidogrel (300 mg in part 1 and $600 \mathrm{mg}$ in part 3) was administered concomitantly with dabigatran etexilate $150 \mathrm{mg}$ twice daily (bid). Test/reference ratios for $\mathrm{AUC}_{\tau, \mathrm{ss}}$ were $135 \%(90 \%$ CI $107-169 \%)$ and $132 \%(90 \%$ CI 112-156\%), respectively. Steady-state dosing of clopidogrel $75 \mathrm{mg}$ qd and dabigatran etexilate $150 \mathrm{mg}$ bid (part 2) demonstrated minor effects on dabigatran pharmacokinetics $\left(\mathrm{AUC}_{\tau, \mathrm{ss}}\right.$ ratio test/reference: $91.9 \%, 90 \%$ CI $78.7-$ $107 \%$ ) or its pharmacokinetic/pharmacodynamic relationships (activated partial thromboplastin time, ecarin clotting time, thrombin time). Similarly, clopidogrel bioavailability remained unchanged by chronic administration of dabigatran etexilate (part 3: ratio test/reference for $\mathrm{AUC}_{0-24}$ was $103 \%$; $90 \%$ CI $80.3-131 \%$ ), as did its pharmacodynamic effects on the inhibition of platelet aggregation.

Conclusions When given concomitantly, dabigatran etexilate and clopidogrel at clinically relevant doses did not appear to have significant effects on the pharmacokinetic and pharmacodynamic profiles of either agent.

Keywords Clopidogrel $\cdot$ Comedication · Dabigatran etexilate · Pharmacodynamics · Pharmacokinetics . Thrombin inhibitor

\section{Introduction}

Anticoagulants and antiplatelet drugs are among the major therapeutic agents in the treatment of coronary artery disease 
and the treatment and prevention of arterial and venous thromboembolic events. Given the different mechanisms of action of these two agents, combining them has the potential for additive and perhaps synergistic reductions in thromboembolic events but may also lead to increased bleeding [1,2].

Dabigatran etexilate (Pradaxa ${ }^{\circledR}$; Boehringer Ingelheim Pharma GmbH \& Co. KG, Ingelheim, Germany) is an oral prodrug that is rapidly converted to dabigatran, a direct thrombin inhibitor [3, 4]. Because of thrombin's multiple roles in coagulation, thrombin inhibitors not only block fibrin formation but also attenuate further thrombin formation and platelet activation [5]. Dabigatran is subject to conjugation with activated glucuronic acid, yielding pharmacologically active glucuronide conjugates that comprise about $20 \%$ of the total dabigatran in plasma $[6,7]$. Dabigatran is not metabolized by hepatic cytochrome $\mathrm{P} 450$ (CYP) isoenzymes and does not affect the metabolism of other drugs that utilize this system. However, the prodrug but not dabigatran is a substrate for the efflux transporter Pgp [8]. Clopidogrel also has been shown to have some affinity for P-gp [9]. Platelet activation can occur via the platelet thromboxane $\mathrm{A}_{2}$ pathway, the adenosine diphosphate (ADP) pathway and via phosphodiesterase.

Clopidogrel inhibits the platelet-surface ADP receptor $\mathrm{P} \mathrm{Y}_{12}$, decreasing platelet activation and aggregation [10]. Clopidogrel, also a prodrug, has no intrinsic antiplatelet activity and requires hepatic CYP metabolic activation to produce its pharmacologically active metabolite, which irreversibly inhibits ADP receptors on platelets [10, 11]. Multiple CYP enzymes have been implicated, although CYP2C19 and CYP3A4 are more important in the formation of the pharmacologically active metabolite $[12,13]$. Polymorphisms in CYP enzymes may contribute to the high variability in responsiveness to clopidogrel. Studies suggest that a high loading dose of clopidogrel may reduce intra-individual variability and enhance responsiveness [14-17], hence use of a clopidogrel $600 \mathrm{mg}$ loading dose is widespread in clinical practice.

Concomitant use of anticoagulants and antiplatelet therapy is frequent in clinical practice [1,2]. Atrial fibrillation patients on anticoagulant therapy for stroke prevention commonly have concomitant conditions such as coronary heart disease and cerebrovascular disease, for which antiplatelet drugs are prescribed. In these patients concerns about increased bleeding risks exist [18]. Accordingly, the potential for increased risk of bleeding when the combination of an anticoagulant and antiplatelet drug is taken is addressed in the label of dabigatran etexilate [8]. This study was conducted to evaluate whether any pharmacokinetic (PK) and/ or pharmacodynamic (PD) interactions exist.

The objectives of this study were to evaluate (1) the PK and PD effects of concomitant administration of multiple doses of clopidogrel $75 \mathrm{mg}$ once daily (qd) (preceded by a loading dose of clopidogrel $300 \mathrm{mg}$ ) with multiple doses of dabigatran etexilate $150 \mathrm{mg}$ twice daily (bid) and (2) the PK and PD effects of concomitant administration of single loading doses of clopidogrel (300 or $600 \mathrm{mg}$ ) with dabigatran etexilate (150 mg bid). Secondary PD parameters evaluated were activated partial thromboplastin time (aPTT), ecarin clotting time (ECT), thrombin time (TT), inhibition of platelet aggregation as well as effects on capillary bleeding time (CBT).

\section{Methods}

\section{Subjects}

Eligible subjects were healthy males aged $18-40$ years, with a body mass index (BMI) of $18.5-29.9 \mathrm{~kg} / \mathrm{m}^{2}$, and judged to be healthy based on medical history, physical examination, vital signs, 12-lead electrocardiogram (ECG) and clinical laboratory tests. Subjects were excluded if they had any of the following: gastrointestinal, hepatic, renal, respiratory, cardiovascular, metabolic, immunological, or hormonal disorders; trauma or surgery within the last month or planned surgery during the trial; risk of bleeding; use of drugs that might affect blood clotting; or use of drugs that might influence the results of the trial (e.g., inhibitors or inducers of P-gp, CYP3A4, CYP2C9, or CYP2C19). All eligible subjects signed written informed consent prior to enrolment. All subjects were genotyped for single nucleotide polymorphisms in the CYP2C19 and CYP2C9 genes.

\section{Study design and treatments}

This open-label drug-drug interaction trial in healthy male subjects was conducted in a single center and included a screening evaluation prior to the conduct of any study procedures and an end-of-study evaluation for all subjects. Prior to study initiation, the trial was reviewed and approved by an independent ethics committee (Ethik-Kommission der Landesärztekammer Baden-Württemberg in Stuttgart, Germany) and competent authority (BfArM, Germany). The year of approval and trial conduct was 2009. The trial was registered as required according to German drug law.

The treatment phase was divided into three separate parts, each with a different set of subjects. Part 1 (pilot study) was an open-label, multiple-dose (for dabigatran etexilate) and single-dose (for clopidogrel), fixed-sequence study. A single dose of clopidogrel $300 \mathrm{mg}$ was given in addition to dabigatran etexilate $150 \mathrm{mg}$ bid in steady state (Table 1). Part 2 (main study) was a randomized, open-label, multiple-dose, crossover study, with three periods of up to 5 days separated by washout periods of at least 14 days. The test treatment consisted of a clopidogrel $300 \mathrm{mg}$ loading dose on day 1 , followed by a $75 \mathrm{mg}$ dose on day 2 , then clopidogrel $75 \mathrm{mg}$ qd in combination with dabigatran etexilate $150 \mathrm{mg}$ bid on 
Table 1 Study design

\begin{tabular}{|c|c|c|c|c|c|}
\hline \multicolumn{6}{|l|}{ Part 1} \\
\hline & Day 1 & \multicolumn{2}{|c|}{ Day 2} & Day 3 & Day 4 \\
\hline $\begin{array}{l}\text { Test } \\
\text { combination } \\
\text { \& reference } \\
\text { dabigatran } \\
n=8\end{array}$ & DE $150 \mathrm{mg}$ bid & \multicolumn{2}{|c|}{ DE $150 \mathrm{mg}$ bid } & DE 150 mg bid & $\begin{array}{c}\text { DE } 150 \mathrm{mg} \mathrm{qd} \\
+ \text { clopidogrel } 300 \mathrm{mg}^{\mathrm{a}}\end{array}$ \\
\hline \multicolumn{6}{|l|}{ Part 2} \\
\hline & \multicolumn{2}{|l|}{ Day 1} & \multicolumn{2}{|c|}{ Day 2} & Day 3-5 \\
\hline $\begin{array}{l}\text { Test } \\
\text { combination } \\
n=24\end{array}$ & \multicolumn{2}{|c|}{ Clopidogrel 300 mg } & \multicolumn{2}{|c|}{ Clopidogrel $75 \mathrm{mg}$} & $\begin{array}{l}\text { Clopidogrel } 75 \text { mg + } \\
\text { DE } 150 \text { mg bid (day 5: } \\
\text { qd) }\end{array}$ \\
\hline \multicolumn{6}{|c|}{ 14-day washout } \\
\hline $\begin{array}{l}\text { Reference } \\
\text { clopidogrel } \\
n=24\end{array}$ & \multicolumn{2}{|c|}{ Clopidogrel 300 mg } & \multicolumn{2}{|c|}{ Clopidogrel 75 mg } & Clopidogrel $75 \mathrm{mg}$ \\
\hline \multicolumn{6}{|c|}{ 14-day washout } \\
\hline $\begin{array}{l}\text { Reference } \\
\text { dabigatran } \\
n=24\end{array}$ & \multicolumn{3}{|l|}{-} & - & $\begin{array}{l}\text { DE } 150 \text { mg bid } \\
\text { (day 5: qd) }\end{array}$ \\
\hline \multicolumn{6}{|l|}{ Part 3} \\
\hline & Day 1 & \multicolumn{2}{|c|}{ Day 2} & Day 3 & Day 4 \\
\hline $\begin{array}{l}\text { Reference } \\
\text { clopidogrel } \\
n=12\end{array}$ & $\begin{array}{l}\text { Clopidogrel } \\
600 \mathrm{mg}\end{array}$ & \multicolumn{2}{|c|}{-} & - & - \\
\hline \multicolumn{6}{|c|}{ 14-day washout } \\
\hline $\begin{array}{l}\text { Reference } \\
\text { dabigatran \& } \\
\text { test } \\
\text { combination } \\
\text { (day 4) }\end{array}$ & DE 150 mg bid & \multicolumn{2}{|c|}{ DE 150 mg bid } & $\underset{b}{D E} 150$ mg bid & $\begin{array}{c}\text { DE } 150 \text { mg qd + } \\
\text { clopidogrel } 600 \text { mg }^{a}\end{array}$ \\
\hline$n=12$ & & & & & \\
\hline
\end{tabular}

$D E$ dabigatran etexilate, bid twice daily, $q d$ once daily

${ }^{\mathrm{a}}$ Test dabigatran pharmacokinetic parameters determined from samples taken after the co-administered doses on day 4

${ }^{\mathrm{b}}$ Reference dabigatran pharmacokinetic parameters determined from samples taken after the morning dose on day 3

days 3-5 (Table 1). Part 3 (main study) was an open-label, multiple-dose (for dabigatran etexilate) and single-dose (for clopidogrel), fixed-sequence study. A single dose of clopidogrel $600 \mathrm{mg}$ was given alone or in addition to dabigatran $150 \mathrm{mg}$ bid at steady state (Table 1).
Although there are no reported interactions of food with dabigatran etexilate or clopidogrel $[8,19]$, the morning medication was administered with about $240 \mathrm{~mL}$ of water following an overnight fast of at least $10 \mathrm{~h}$, and no food was allowed until $4 \mathrm{~h}$ after drug administration. According to the 
twice-daily regimen dabigatran etexilate was similarly administered again $12 \mathrm{~h}$ later. Subjects were not allowed to lie down during the $2 \mathrm{~h}$ following drug administration, and water was limited for $1 \mathrm{~h}$ before and after drug administration. On dosing days a light non-standardized breakfast was given $1 \mathrm{~h}$ after morning drug administration. On profile days, no food was given until $4 \mathrm{~h}$ after administration. No concomitant therapy was allowed during the study, except for prophylactic thyroid hormone replacement and for symptomatic therapy of adverse events (AEs) in need of treatment.

\section{Study endpoints}

The primary endpoints for $\mathrm{PK}$ were the maximum measured plasma concentration of the analyte at steady state $\left(\mathrm{C}_{\text {max,ss }}\right)$ and the area under the concentration-time curve over one dosing interval $(0-12 \mathrm{~h}$ for dabigatran and $0-24 \mathrm{~h}$ for clopidogrel) at steady state $\left(\mathrm{AUC}_{\tau, \mathrm{ss}}\right)$ for free and total dabigatran (free and glucuronide-conjugated) and for clopidogrel and its inactive metabolite (SR26334), and the $\mathrm{C}_{\max }$ and the AUC from 0 to $24 \mathrm{~h}\left(\mathrm{AUC}_{0-24}\right)$ of clopidogrel and SR26334 after the 300 or $600 \mathrm{mg}$ clopidogrel loading doses.

The primary endpoints for PD were area under the effect curve of ADP-induced inhibition of platelet aggregation (IPA) at steady state of clopidogrel over one dosing interval from 0 $24 \mathrm{~h}$ after dosing $\left(\mathrm{AUEC}_{\mathrm{IPA}, \tau, \mathrm{ss}}\right)$; maximum percentage change compared with baseline in ADP-induced platelet aggregation at steady state of clopidogrel $\left(\mathrm{E}_{\mathrm{max}, \mathrm{IPA}, \mathrm{ss}}\right)$; AUEC from 0 to $24 \mathrm{~h}$ (AUEC $\left.{ }_{\text {IPA }, 0-24}\right)$ after the loading dose of clopidogrel $600 \mathrm{mg}$; and the maximum percentage change compared with baseline in ADP-induced platelet aggregation from 0 to $24 \mathrm{~h}$ $\left(E_{\text {max }, I P A, 0-24}\right)$ after the loading dose of clopidogrel $600 \mathrm{mg}$.

The secondary endpoints included other PK parameters and the effects of clopidogrel on the PD of dabigatran assessed by ECT, aPTT, TT (including maximum effect ratio, $\mathrm{ER}_{\max }$ ) as well as the $\mathrm{CBT}$.

\section{PK/PD determinations (bioanalytics)}

For PK parameter evaluations, blood samples were taken for the determination of plasma concentrations of free, nonconjugated dabigatran, total dabigatran (after alkaline cleavage of conjugates), and the prodrug dabigatran etexilate, and of clopidogrel and SR26334.

The following PD parameters were also evaluated:

- For clopidogrel, ADP-induced IPA was determined at predefined time points.

- Capillary bleeding times were assessed (part 2 and part 3 of the study) before clopidogrel administration, 2, 4, and $12 \mathrm{~h}$ after clopidogrel administration, and following administration of dabigatran etexilate alone.
Blood samples were taken before and at specified intervals up to $24 \mathrm{~h}$ after the morning clopidogrel dose, and before and up to $24 \mathrm{~h}$ after the morning and evening dabigatran etexilate dose. Timings of PK/PD sampling are shown in Supplementary Table 1.

Blood samples $(\sim 2.7 \mathrm{~mL}$ for dabigatran and $\sim 4.0 \mathrm{~mL}$ for clopidogrel) were collected into tubes containing potassium ethylenediaminetetraacetic acid for PK analysis. Samples were centrifuged, and the resulting plasma samples were separated and stored at $-70^{\circ} \mathrm{C}$ or below.

Plasma concentrations of free, nonconjugated dabigatran; total dabigatran (sum of free and conjugated dabigatran measured after alkaline cleavage of conjugates); the prodrug dabigatran etexilate; clopidogrel; and SR26334 were determined by validated high-performance liquid chromatography tandem mass spectrometry (HPLC-MS/MS) at AAI Pharma Deutschland (Neu-Ulm, Germany). The calibration curves for free and total dabigatran covered a range from 1.00 to $400 \mathrm{ng} / \mathrm{mL}$ plasma in undiluted samples. The calibration curves were linear over the calibration range and no interference from endogenous compounds was observed. Maximum imprecision and inaccuracy for quality control samples at concentrations of 3,30 , and $320 \mathrm{ng} / \mathrm{mL}$ were 6.62 and $+5.86 \%$, respectively. For the prodrug, maximum imprecision and inaccuracy were 6.63 and $+2.83 \%$, respectively.

Calibration curves for clopidogrel and SR26334 covered concentration ranges of $0.01-10 \mathrm{ng} / \mathrm{mL}$ and $0.02-20 \mu \mathrm{g} / \mathrm{mL}$, respectively, with an inaccuracy generally below $4 \%$ and imprecision below 9\%. For blood coagulation parameters aPTT, ECT, and TT (PD analyses), $\sim 3 \mathrm{~mL}$ of blood were collected in sodium citrate monovettes at the time points indicated for PK analyses. The blood samples were centrifuged, frozen, and stored at $-20^{\circ} \mathrm{C}$ or below. The aPTT, ECT, and TT parameters were analyzed on an MC10PLUS coagulometer using validated methods by BiochemA, Riegel, Germany. aPTT was measured using a kit from Roche Diagnostics (Mannheim, Germany) according to manufacturer's instructions, and the ECT assay utilized ecarin from Pentapharm (Basel, Switzerland). Thrombin inhibition (TT), anti-factor IIa, was measured by the Hemoclot Thrombin Inhibitors Assay ${ }^{\circledR}\left(\right.$ Hemoclot $^{\circledR}$ TT \#CK002K, HYPHEN BioMed, Neuville-sur-Oise, France) according to the manufacturer's instructions. The Hemoclot kit was used for the quantitative measurement of direct thrombin inhibitors in plasma, with a clotting method based on the inhibition of a constant and defined concentration of thrombin.

For platelet aggregation testing, $\sim 9 \mathrm{~mL}$ of blood was collected into a $10 \mathrm{~mL}$ monovette containing citrate to yield a final concentration of $10.6 \mathrm{mM}$. Platelet-rich plasma (PRP) was prepared by centrifugation and removed from the red-cell sediment. Approximately $0.5 \mathrm{~mL}$ platelet-poor plasma (PPP) was prepared from PRP by further centrifugation. Inhibition of platelet aggregation was performed by 
light transmission aggregometry in citrated PRP, using an 8channel platelet aggregation profiler (PAP 8) aggregometer (möLab, Germany). The PRP ( $0 \%$ light transmission) and PPP (100\% light transmission) served as reference. After baseline adjustment, ADP in a final concentration of $20 \mu \mathrm{M}$ was added and aggregation recorded for $6 \mathrm{~min}$. Maximum aggregation (\%) within the first 6 min after addition of ADP was determined.

The bleeding time was assessed by single measurements on the forearm using the Surgicutt ${ }^{\circledR}$ Bleeding Time Device (Product Number SUB50, International Technidyne, Edison, NJ, USA). Using a Surgicutt device, a standardized incision of $5 \mathrm{~mm}$ length and $1 \mathrm{~mm}$ depth was made in the skin. Every $30 \mathrm{~s}$, the blood flow was wicked away cautiously with filter paper, so that the platelet plug remained intact, until the bleeding stopped. Normal bleeding time was under $8 \mathrm{~min}$.

\section{Safety}

Safety was assessed by medical examination, pulse rate, blood pressure, ECG, clinical and laboratory parameters, AEs, and an assessment of clinical global tolerability (4-point scale: good, satisfactory, not satisfactory, and bad).

\section{Statistical methods}

The aim of the trial was to estimate the relative bioavailability (ratio of exposure: test/reference) and its 90\% confidence interval $(\mathrm{CI})$ regarding $\mathrm{PK}$ and PD parameters (as listed below). Different test and reference treatments were compared by applying the average bioequivalence method. Point estimates for the test/reference ratios and the corresponding 90\% CIs were calculated using an analysis of variance (ANOVA) based on the logarithmic scale regarding PK parameters (multiplicative model) and on the original scale for PD parameters (additive model). The ANOVA model included effects accounting for the following sources of variation: "sequence," "subject within sequence," "period," and "treatment" (crossover design of part 2). The effect "subject within sequence" was considered as random, whereas the other effects were considered as fixed. For parts 1 and 3 "sequence" was not considered because of the fixed sequence design. Two-sided 90\% CIs for the test/ reference ratios were interpreted exploratively, and no statistical hypotheses were tested in a confirmatory sense.

In pilot part 1 and main part 3, the following primary PK and PD parameters were compared intra-individually:

- $\mathrm{AUC}_{\tau, \mathrm{ss}}$ and $\mathrm{C}_{\text {max,ss }}$ of total dabigatran

- $\mathrm{C}_{\max }$ and the AUC from 0 to $24 \mathrm{~h}\left(\mathrm{AUC}_{0-24}\right)$ of clopidogrel and inactive metabolite SR26334

- AUEC $_{\text {IPA,0-24 }}$ and $\mathrm{E}_{\max , I P A, 0-24}$
In main part 2 , the following primary PK or PD parameters were compared intra-individually:

- $\quad \mathrm{AUC}_{\tau, \mathrm{ss}}$ and $\mathrm{C}_{\text {max,ss }}$ of total dabigatran, clopidogrel, and inactive metabolite SR26334

- $\mathrm{AUEC}_{\mathrm{IPA}, \tau, \mathrm{ss}}$ and $\mathrm{E}_{\text {max,IPA,ss }}$ (syn. to AUEC $\mathrm{APA}, 0-24_{\mathrm{I}}$ and $\mathrm{E}_{\max , I P A, 0-24}$ at steady state)

AUEC and $\mathrm{ER}_{\max }$ of aPTT, ECT, and TT as well as CBT, and safety and tolerability were assessed descriptively as secondary parameters.

For the CBT individual listings including the baseline value, the maximum value of the post-dose measurements, and the corresponding time of the maximum value were provided. Frequency tables of the three categories $(<10$, $10-30,>30 \mathrm{~min}$ ) for the maximum CBT values were provided (part 2 and part 3 ).

Sample sizes of 8 subjects in part 1 and 12 subjects in part 3 of the trial were considered sufficient to achieve the exploratory aims. The sample size of 24 subjects in part 2 was chosen to ensure that the estimation of ratios is precise. The desired precision is represented by the half-width of the $90 \%$ confidence interval of the point estimate on the logarithmic scale. In previous single-dose studies, intraindividual variabilities ( $\mathrm{gCVs}$ ) ranging from about 40 to $50 \%$ were observed for PK exposure parameters. The gCV after multiple dosing can be expected to be lower. In case of a $\mathrm{gCV}$ of $35 \%$, a $90 \% \mathrm{CI}$ for the ratio of the test/reference means for a PK parameter would be obtained with $95 \%$ probability and a desired precision of 0.2231 (on the logarithmic scale). For a ratio of $100 \%$, this precision corresponds to an interval of 80 to $125 \%$.

The calculation was performed using the MOC3 routine from commercial software nQuery Advisor [20].

\section{Results}

Study subjects (parts 1, 2, and 3)

A total of 44 healthy male volunteers entered the study and were treated: 8 subjects in part 1, 24 in part 2, and 12 in part 3. A summary of demographic and baseline characteristics is shown in Table 2. All subjects in the trial were white, except for one who was of American-Indian/Alaska native ethnic origin. Genotyping revealed that three subjects were homozygous for the deficient $* 2$ allele of $C Y P 2 C 19$, nine were heterozygous carriers of the $C Y P 2 C 19 * 2$ allele, four subjects had the CYP2C19*17 allele (leading to higher CYP2C19 activity), and two subjects carried only low-activity alleles *2 or *3 of CYP 2 C9, whereas 11 showed the CYP $2 C 9^{*} 1 / 2$ or *1/ *3 genotype. All other subjects were genotyped as normal (extensive) metabolizers. Forty subjects completed the trial. 
Table 2 Demographic and other baseline characteristics

\begin{tabular}{llll}
\hline & Part $1(n=8)$ & Part 2 $(n=24)$ & Part 3 $(n=12)$ \\
\hline $\begin{array}{l}\text { Age, years, mean } \pm \text { SD (range) } \\
\text { Ethnicity, } n(\%)\end{array}$ & $28.9 \pm 4.1(22-33)$ & $31.5 \pm 5.5(23-40)$ & $32.8 \pm 5.6(22-40)$ \\
White & $8(100.0)$ & $24(100.0)$ & $11(91.7)$ \\
American Indian/Alaska native & 0 & 0 & $1(8.3)$ \\
Weight, kg, mean \pm SD (range) & $79.6 \pm 9.9(69-96)$ & $80.4 \pm 7.4(64-91)$ & $81.6 \pm 9.4(68-100)$ \\
BMI, kg/m ${ }^{2}$, mean \pm SD (range) & $24.89 \pm 2.52(21.8-29.4)$ & $24.92 \pm 2.32(19.3-28.7)$ & $26.45 \pm 1.73(24.1-29.5)$ \\
Smokers, $n(\%)$ & & & $5(41.7)$ \\
Never smoked & $3(37.5)$ & $15(62.5)$ & $1(8.3)$ \\
Ex-smoker & $2(25.0)$ & $8(33.3)$ & $6(50.0)$ \\
Current smoker & $3(37.5)$ & $1(4.2)$ & $1(8.3)$ \\
Alcohol intake, $n(\%)$ & $4(50.0)$ & $13(54.2)$ & $11(91.7)$ \\
Non-drinker & $4(50.0)$ & $11(45.8)$ & \\
Drinker, no interference & & & \\
\hline
\end{tabular}

$B M I$ Body mass index, $S D$ standard deviation

\section{Part I}

\section{PK parameters}

Maximum plasma concentrations of free and total dabigatran were increased when clopidogrel $300 \mathrm{mg}$ was coadministered with dabigatran etexilate $150 \mathrm{mg}$ compared with concentrations observed when dabigatran etexilate was administered alone. The shapes of the plasma-concentration-time curves of free and total dabigatran and clopidogrel and SR26334 were similar with or without coadministration of $300 \mathrm{mg}$ clopidogrel. $\mathrm{C}_{\max , \mathrm{ss}}$ increased by $69 \%$ when clopidogrel $300 \mathrm{mg}$ was coadministered with dabigatran $150 \mathrm{mg}$ bid. The corresponding change in $\mathrm{AUC}_{\tau, \mathrm{ss}}$ of total dabigatran was a $35 \%$ increase when clopidogrel $300 \mathrm{mg}$ was coadministered with dabigatran $150 \mathrm{mg}$ bid (Table 3). Clopidogrel was not associated with other changes in total dabigatran PK parameters.

$\mathrm{AUC}_{0-24}$ for clopidogrel with dabigatran etexilate $150 \mathrm{mg}$ bid was $8,580 \mathrm{pg} \cdot \mathrm{h} / \mathrm{mL}$ and for SR 26334 with dabigatran etexilate $150 \mathrm{mg}$ bid was $35,400 \mathrm{pg} \mathrm{h} / \mathrm{mL}$. Large variability [geometric coefficient of variation (gCV)] between 171 and $258 \%$ with respect to the primary PK parameters of clopidogrel was observed, although the variability for the major circulating metabolite SR26334 was low (13-21\% gCV).

\section{PD parameters}

Inhibition of platelet aggregation A maximum of about $50 \%$ inhibition of ADP-dependent platelet aggregation $\left(\mathrm{E}_{\max }\right)$ was observed after a single dose of clopidogrel $300 \mathrm{mg}$ (part 1; data not shown).

Blood coagulation parameters (aPTT, ECT, and anti-factor IIa) In part 1, the effect of dabigatran on these coagulation parameters was slightly increased when a single dose of clopidogrel $300 \mathrm{mg}$ was added to steady-state dabigatran etexilate $150 \mathrm{mg}$ bid. The greatest change was seen in the gMean AUEC $_{\tau, \mathrm{ss}}$ of aPTT, which was increased by about $30 \%$ when dabigatran etexilate was administered with clopidogrel.

Table 3 Part 1. Adjusted geometric means (gMean) and gMean ratios of total dabigatran pharmacokinetic parameters when dabigatran etexilate $150 \mathrm{mg}$ was administered twice daily with or without a single dose of clopidogrel $300 \mathrm{mg}$

\begin{tabular}{llllc}
\hline Parameter & $\begin{array}{l}\text { DE } 150 \mathrm{mg}+\text { clopidogrel } 300 \mathrm{mg} \\
\text { Test, gMean }(n=8)\end{array}$ & $\begin{array}{l}\text { DE 150 mg } \\
\text { Reference, gMean } \\
(n=8)\end{array}$ & $\begin{array}{c}\text { Ratio test/reference, } \\
\% \text { gMean }\end{array}$ & $\begin{array}{c}90 \% \mathrm{Cl} \\
\text { Intra-individual } \\
\mathrm{gCV}, \%\end{array}$ \\
\hline Total dabigatran & & & & 135 \\
$\mathrm{AUC}_{\tau, \mathrm{ss}}, \mathrm{ng} \cdot \mathrm{h} / \mathrm{mL}$ & 979 & 727 & 169 & 107,169 \\
$\mathrm{C}_{\mathrm{max}, \mathrm{ss}}, \mathrm{ng} / \mathrm{mL}$ & 184 & 109 & 74.4 & 24.4 \\
$\mathrm{CL} / \mathrm{F}$ & & 24.0 \\
\hline
\end{tabular}

$A U C_{\tau, s s}$ Area under the concentration-time curve of the analyte in plasma at steady state over a uniform dosing interval $\tau, C I$ confidence interval, $C L / F_{s s}$ apparent clearance of analyte in plasma following extravascular administration, $C_{\max , s s}$ maximum plasma concentration at steady state, $D E$ dabigatran etexilate, $g C V$ geometric coefficient of variation 
Table 4 Part 2. Adjusted geometric means (gMean) and gMean ratios of total dabigatran, clopidogrel, and SR26334 multiple dose pharmacokinetic parameters when dabigatran etexilate (DE) $150 \mathrm{mg}$ twice daily (bid) was administered in combination with clopidogrel $75 \mathrm{mg}$ once daily (qd) (preceded by a $300 \mathrm{mg}$ loading dose) versus dabigatran etexilate $150 \mathrm{mg}$ bid alone or clopidogrel $75 \mathrm{mg}$ qd alone

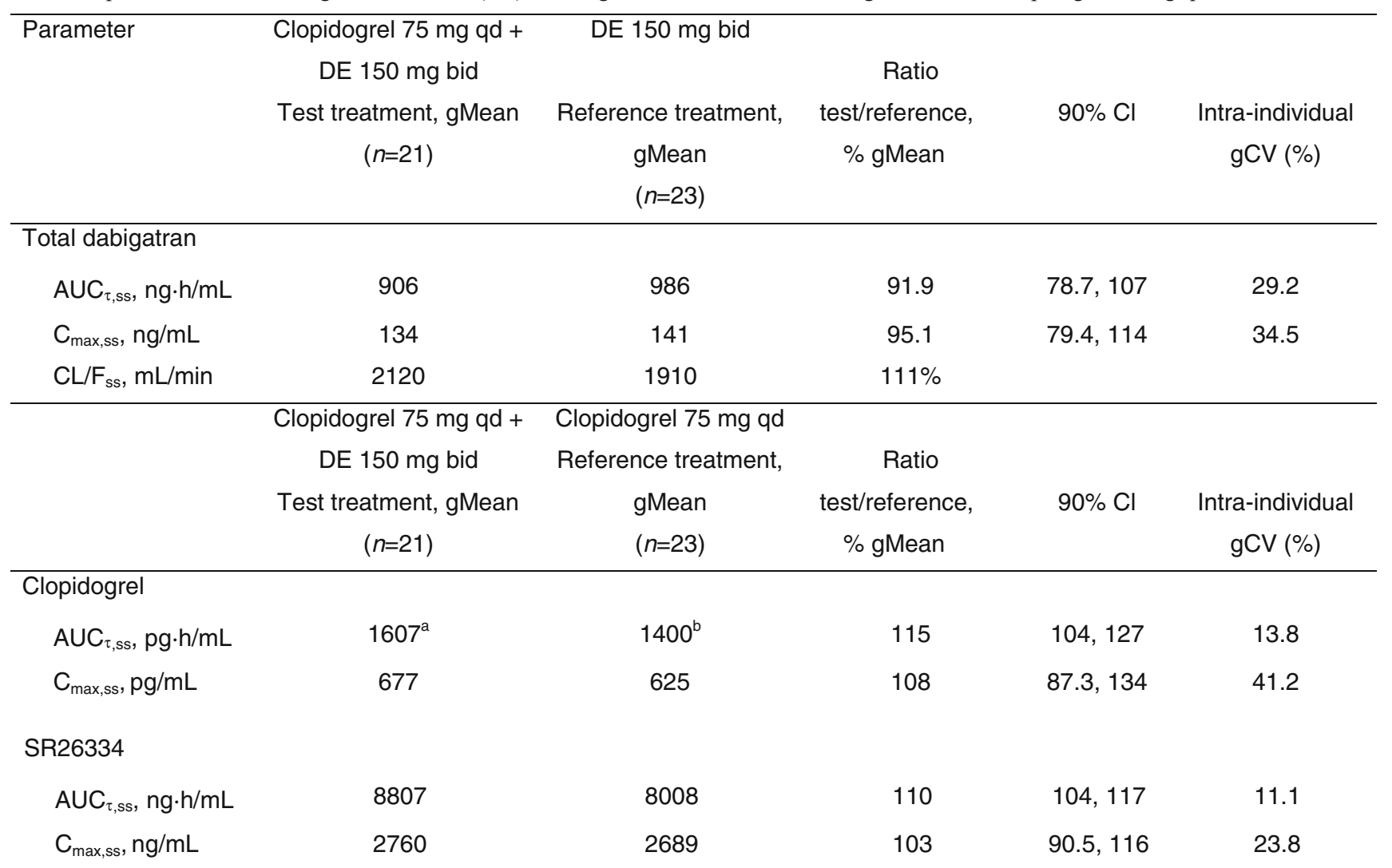

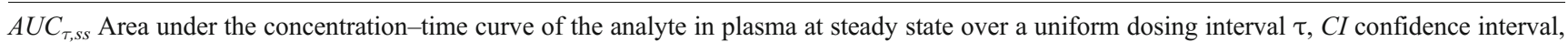
$C L / F_{s s}$ apparent clearance of analyte in plasma following extravascular administration, $C_{\max , s s}$ maximum plasma concentration at steady state, $g C V$ geometric coefficient of variation

${ }^{\mathrm{a}} n=14$

${ }^{\mathrm{b}} n=17$

Part 2

\section{PK parameters}

There was no apparent change in the shape of the plasma concentration-time curves of dabigatran in subjects who received dabigatran etexilate $150 \mathrm{mg}$ alone or after multiple doses of clopidogrel $75 \mathrm{mg}$ qd (preceded by a loading dose of $300 \mathrm{mg}$ ). Similarly, dabigatran etexilate $150 \mathrm{mg}$ bid had no influence on the shape of the plasma concentration-time curves of clopidogrel and SR26334 after multiple doses of clopidogrel (Supplementary Fig. 1a, b).

Repeated doses of clopidogrel had no effect on the steadystate PK $\left(\mathrm{AUC}_{\tau, \mathrm{ss}}\right.$ and $\mathrm{C}_{\text {max,ss }}$ ) of free and total dabigatran, and intra-individual variations were similar in each case. Clopidogrel had no effect on dabigatran etexilate glucuronidation. Table 4 shows the ratios and confidence intervals of the PK parameters of dabigatran etexilate $150 \mathrm{mg}$ bid when given in combination with clopidogrel $75 \mathrm{mg}$ qd (preceded by a $300 \mathrm{mg}$ loading dose) versus dabigatran $150 \mathrm{mg}$ alone.
The corresponding ratios and confidence intervals of the PK parameters of clopidogrel and SR26334 with dabigatran etexilate $150 \mathrm{mg}$ bid given in combination with clopidogrel $75 \mathrm{mg}$ qd (preceded by a $300 \mathrm{mg}$ loading dose) versus clopidogrel $75 \mathrm{mg}$ alone showed that concomitant administration did not alter exposure to the parent drug or the major metabolite.

The time to $\mathrm{C}_{\max }\left(\mathrm{t}_{\max , \mathrm{ss}} ; 2 \mathrm{~h}\right)$ and half-life $\left(\mathrm{t}_{1 / 2, \mathrm{ss}} ; \sim 9.5 \mathrm{~h}\right)$ were similar in subjects receiving multiple doses of dabigatran etexilate $150 \mathrm{mg}$ alone or in combination with repeated oral doses of clopidogrel $75 \mathrm{mg}$ (300 mg loading dose).

\section{$P D$ parameters}

Inhibition of platelet aggregation Coadministration of dabigatran etexilate $150 \mathrm{mg}$ did not alter the maximum ADPdependent platelet aggregation achieved after a single dose of clopidogrel $300 \mathrm{mg}$ (Fig. 1). Following repeated doses of clopidogrel $75 \mathrm{mg}$ (preceded by $300 \mathrm{mg}$ loading dose), the $\mathrm{E}_{\mathrm{max}, \mathrm{ss}}$ 


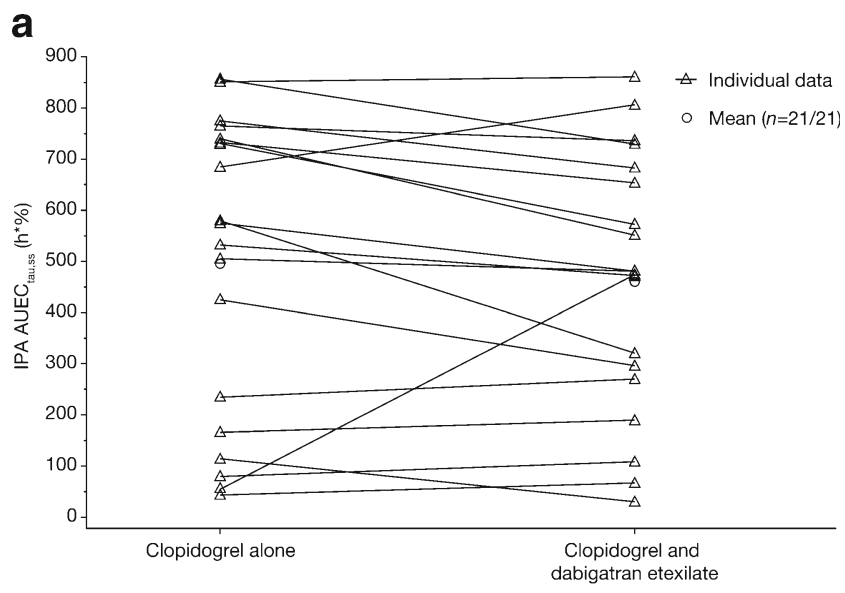

b

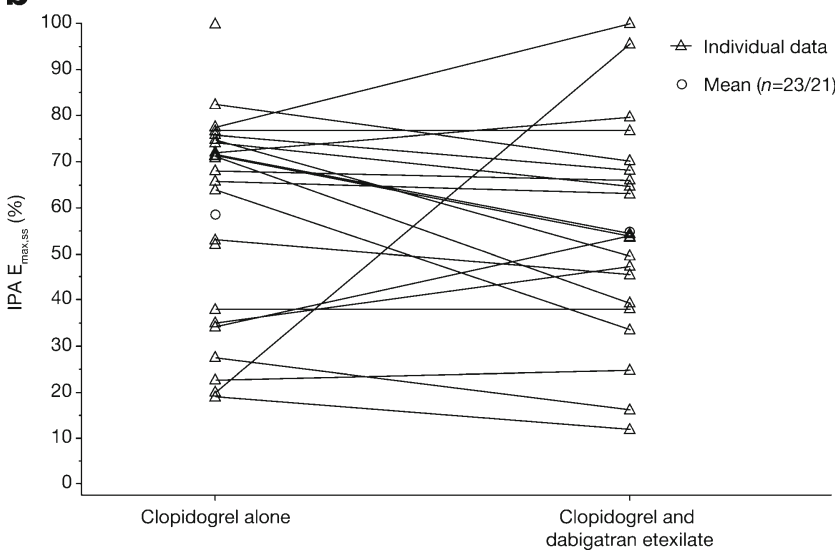

Fig. 1a, b Part 2. Effect of comedication with dabigatran on inhibition of platelet aggregation (IPA) by clopidogrel. Comparison between clopidogrel monotherapy and clopidogrel + dabigatran of individual and geometric mean (gMean) $\mathrm{AUEC}_{\tau, \mathrm{ss}}$ (a) and $\mathrm{E}_{\mathrm{max}, \mathrm{ss}}$ values of IPA (b). $A U E C_{\tau, s s}$ Area under the effect curve of inhibition of platelet aggregation (at steady state), $E_{\max , s s}$ maximum percentage change (compared with baseline) in adenosine triphosphate-induced platelet aggregation of clopidogrel (at steady state)

of IPA was approximately $50 \%$ with or without coadministration of multiple doses of dabigatran etexilate $150 \mathrm{mg}$ bid (part 2).

Analyses revealed modestly lower $\mathrm{AUEC}_{\tau, \mathrm{ss}}$ and $\mathrm{E}_{\mathrm{max}, \mathrm{ss}}$ of IPA with regard to the comparison of the combined treatment with multiple doses of clopidogrel $75 \mathrm{mg}$ qd (preceded by a loading dose of $300 \mathrm{mg}$ ) and multiple doses of dabigatran etexilate $150 \mathrm{mg}$ versus treatment with multiple doses of clopidogrel alone (Table 6).

Blood coagulation parameters (aPTT, ECT and anti-factor IIa) In part 2, AUEC $\mathrm{IPA}, \tau, \mathrm{ss}_{\text {s }}$ and $\mathrm{ER}_{\max , \mathrm{ss}}$ of TT, ECT, and aPTT were not altered after concomitant administration of repeated doses of clopidogrel $75 \mathrm{mg}$ qd (300 $\mathrm{mg}$ loading dose) and multiple doses of dabigatran etexilate $150 \mathrm{mg}$ bid. A trend towards a higher IPA activity was observed in subjects with the CYP2C19*17 allele. CYP2C19*17 is associated with faster metabolism of clopidogrel to its pharmacologically active metabolite [21]. CYP2C9 polymorphism was not associated with differences in maximum IPA activities.

In evaluation of PK/PD, a linear relationship between plasma concentration and coagulation prolongation was observed for both TT and ECT, whereas the relationship was nonlinear between plasma concentration and aPTT. No effect of clopidogrel on the PK/PD relationship was found when dabigatran etexilate was given alone or in combination with clopidogrel (Fig. 2).

Capillary bleeding time In part 2, the maximum CBT was prolonged by any treatment that included clopidogrel. However, no difference could be observed between clopidogrel monotherapy and clopidogrel + dabigatran etexilate combination therapy. Dabigatran alone did not prolong the CBT.

Part 3

\section{PK parameters}

The maximum plasma concentrations of free and total dabigatran were increased when clopidogrel $600 \mathrm{mg}$ was coadministered with dabigatran etexilate $150 \mathrm{mg}$ bid at steady state. However, the general shape of the plasma concentration-time profiles of free and total dabigatran was not altered. There was no detectable difference between the plasma concentration-time profiles of clopidogrel or SR26334 when clopidogrel $600 \mathrm{mg}$ was administered alone or with dabigatran etexilate $150 \mathrm{mg}$ bid. Clopidogrel had no effect on dabigatran glucuronidation (Supplementary Fig. 2a, b).

Calculation of geometric mean (gMean) ratios showed that the bioavailability $\left(\mathrm{AUC}_{\tau, \mathrm{ss}}\right)$ of total dabigatran was increased by $32 \%$ when dabigatran etexilate $150 \mathrm{mg}$ bid was administered together with a single dose of clopidogrel $600 \mathrm{mg}$. The maximum plasma concentration $\left(\mathrm{C}_{\max , \mathrm{ss}}\right)$ of total dabigatran was similarly affected, increasing by $43 \%$ (Table 5). The effect of clopidogrel on the exposure of free dabigatran was similar to that observed with total dabigatran. The $\mathrm{AUC}_{0-24}$ and $\mathrm{C}_{\max }$ for clopidogrel and SR26334 after clopidogrel $600 \mathrm{mg}$ alone were only minimally affected by coadministration with dabigatran $150 \mathrm{mg}$ bid at steady state (Table 5).

\section{PD parameters}

Inhibition of platelet aggregation A maximum of about $60 \%$ inhibition of ADP-dependent platelet aggregation $\left(\mathrm{E}_{\max }\right)$ was observed after a single dose of clopidogrel $600 \mathrm{mg}$ (part 3; Table 6). The $\mathrm{AUEC}_{\tau, \mathrm{ss}}$ in participants taking multiple doses of dabigatran etexilate $150 \mathrm{mg}$ concomitantly with a single dose of clopidogrel $600 \mathrm{mg}$ was 
Fig. 2a-c Part 2. Effect of clopidogrel on ecarin clotting time (ECT) ratio (a), activated partial thromboplastin time (aPTT) ratio (b), and TT (anti-factor IIa) ratio (c) after multiple oral administrations of dabigatran etexilate $150 \mathrm{mg}$ twice daily with or without coadministration of repeated doses of $75 \mathrm{mg}$ clopidogrel once daily (300 mg loading dose) a

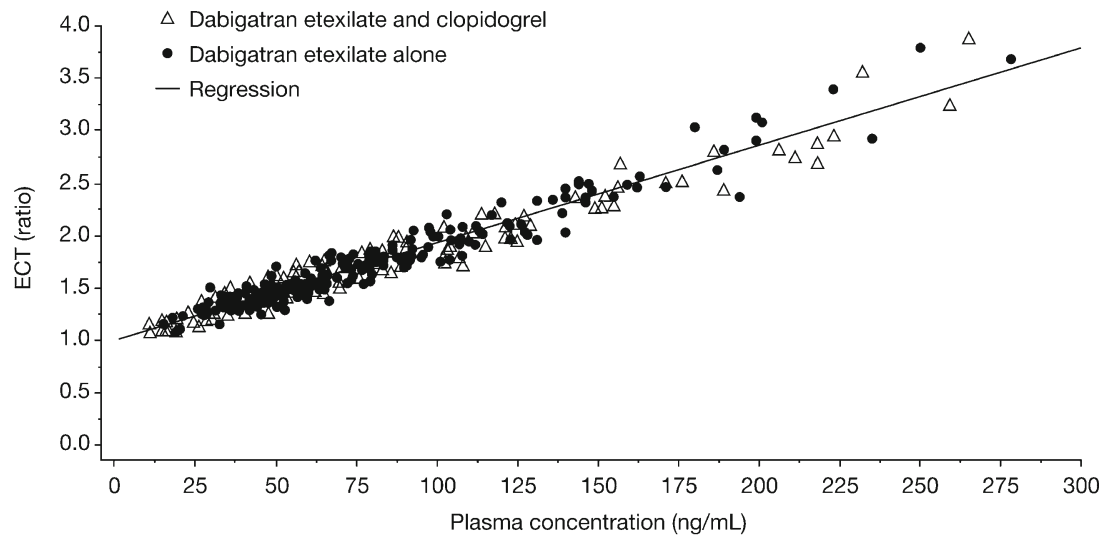

b

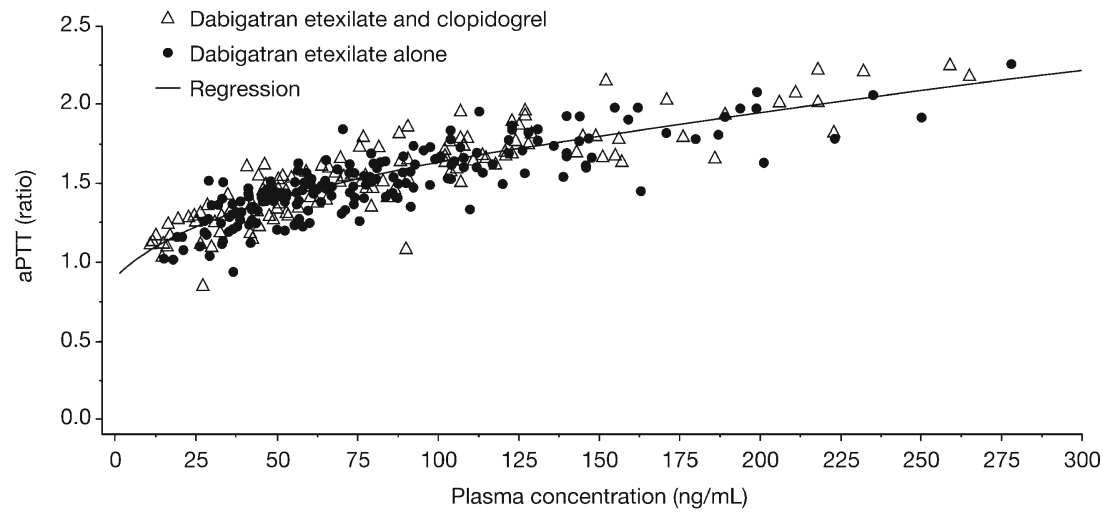

C

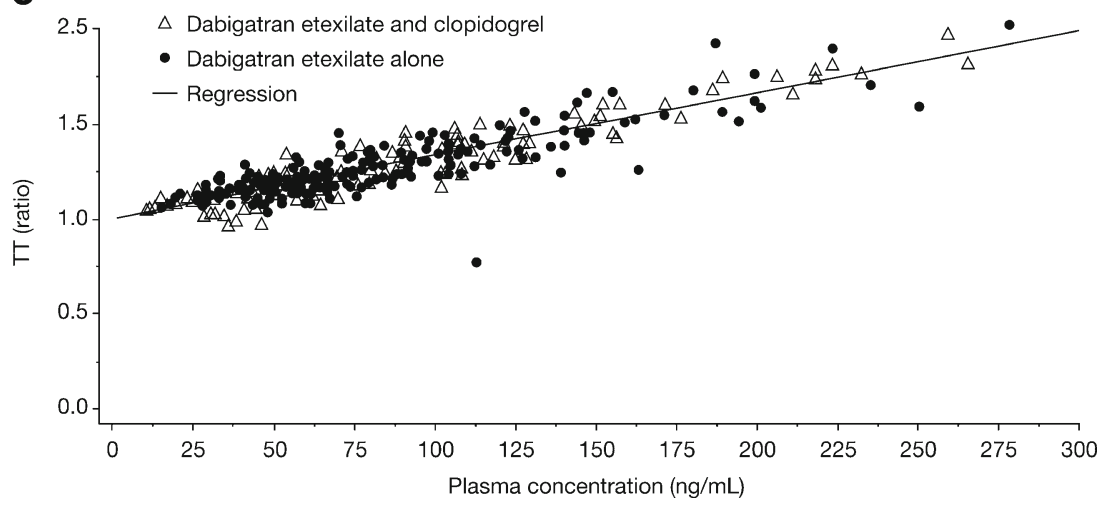

lower than that of the treatment group taking a single dose of clopidogrel $600 \mathrm{mg}$ (1,179 versus 1,264, respectively; 90\% CI -293 to 124 ) (Table 6).

Blood coagulation parameters (aPTT, ECT, and anti-factor IIa) In part 3, the dabigatran-related effect on TT, ECT, and aPTT after administration of dabigatran etexilate $150 \mathrm{mg}$ bid was slightly increased when a single dose of clopidogrel $600 \mathrm{mg}$ was coadministered. The greatest change (approximately $36.5 \%$ ) was seen in the $\mathrm{AUEC}_{\tau, \mathrm{ss}}$ of aPTT, when dabigatran etexilate was administered with clopidogrel.
Capillary bleeding time In part 3, the coadministration of dabigatran etexilate $150 \mathrm{mg}$ bid with clopidogrel $600 \mathrm{mg}$ did not increase the CBT compared with a single dose of clopidogrel $600 \mathrm{mg}$ given alone.

Safety (parts 1, 2, and 3)

All AEs were of mild or moderate intensity. All events resolved by the end of the trial, except for an ongoing condition of hemorrhoids in one subject in part 2. There were no deaths, serious AEs, or AEs of severe intensity. 
Table 5 Part 3. Adjusted geometric means (gMean) and gMean ratios of total dabigatran, clopidogrel, and SR26334 pharmacokinetic parameters when dabigatran etexilate (DE) $150 \mathrm{mg}$ twice daily (bid) was administered in combination with a single dose of clopidogrel $600 \mathrm{mg}$ versus dabigatran $150 \mathrm{mg}$ bid alone or clopidogrel $600 \mathrm{mg}$ alone

\begin{tabular}{|c|c|c|c|c|c|}
\hline Parameter & $\begin{array}{c}\text { DE } 150 \mathrm{mg} \text { bid + } \\
\text { clopidogrel } 600 \mathrm{mg} \\
\text { Test treatment, gMean } \\
\qquad(n=11)\end{array}$ & $\begin{array}{l}\text { Reference treatment, } \\
\qquad \begin{array}{l}\text { gMean } \\
(n=11)\end{array}\end{array}$ & $\begin{array}{c}\text { Ratio } \\
\text { test/reference, } \\
\% \text { gMean }\end{array}$ & $90 \% \mathrm{Cl}$ & $\begin{array}{c}\text { Intra-individual } \\
\text { gCV (\%) }\end{array}$ \\
\hline \multicolumn{6}{|l|}{ Total dabigatran } \\
\hline$A \cup C_{\tau, s s}, \mathrm{ng} \cdot \mathrm{h} / \mathrm{mL}$ & 1180 & 894 & 132 & 112,156 & 21.9 \\
\hline $\mathrm{C}_{\max , \mathrm{ss}}, \mathrm{ng} / \mathrm{mL}$ & 188 & 131 & 143 & 120,170 & 23.1 \\
\hline \multirow{2}{*}{$\mathrm{CL} / \mathrm{F}_{\mathrm{ss}}, \mathrm{mL} / \mathrm{min}$} & 1590 & 2100 & 76 & & \\
\hline & $\begin{array}{c}\text { DE } 150 \mathrm{mg} \text { bid + } \\
\text { clopidogrel } 600 \mathrm{mg} \\
\text { Test treatment, gMean } \\
\qquad(n=11)\end{array}$ & $\begin{array}{l}\text { Clopidogrel } 600 \mathrm{mg} \\
\text { Reference treatment, } \\
\qquad \begin{array}{l}\text { gMean } \\
(n=12)\end{array}\end{array}$ & $\begin{array}{c}\text { Ratio } \\
\text { Test/reference, } \\
\% \text { gMean }\end{array}$ & $90 \% \mathrm{Cl}$ & $\begin{array}{l}\text { Intra-individual } \\
\text { gCV (\%) }\end{array}$ \\
\hline \multicolumn{6}{|l|}{ Clopidogrel } \\
\hline $\mathrm{AUC}_{0-24}, \mathrm{pg} \cdot \mathrm{h} / \mathrm{mL}$ & 10840 & 10574 & 103 & $80.3,131$ & 32.5 \\
\hline $\mathrm{C}_{\max }, \mathrm{pg} / \mathrm{mL}$ & 4003 & 4013 & 99.8 & $67.4,148$ & 54.6 \\
\hline $\mathrm{CL} / \mathrm{F}_{\mathrm{ss}}, \mathrm{mL} / \mathrm{min}$ & 931000 & 911000 & 102 & & \\
\hline \multicolumn{6}{|l|}{ SR26334 } \\
\hline $\mathrm{AUC}_{0-24}, \mathrm{ng} \cdot \mathrm{h} / \mathrm{mL}$ & 82.5 & 84.3 & 97.8 & $83.5,115$ & 20.8 \\
\hline $\mathrm{C}_{\max }, \mathrm{ng} / \mathrm{mL}$ & 18505 & 21604 & 85.7 & $68.3,107$ & 30.4 \\
\hline
\end{tabular}

$A U C_{\tau, s s}$ Area under the concentration-time curve of the analyte in plasma at steady state over a uniform dosing interval $\tau, C I$ confidence interval, $C_{\max , s s}$ maximum plasma concentration at steady state, $C L / F_{s s}$ apparent clearance of analyte in plasma following extravascular administration, $g C V$ geometric coefficient of variation

The most frequently reported AEs in all study parts were nervous system disorders, specifically headache. Four subjects reported AEs considered related to the study drugs. These were hematoma (part 2: one subject, clopidogrel $75 \mathrm{mg}$; one subject, during washout after the first treatment period), hematuria (part 2: one subject, clopidogrel+dabigatran etexilate), and rash, i.e., exanthema on both hands (part 3: one subject, dabigatran etexilate+clopidogrel).

Overall, four subjects discontinued treatment prematurely. In part 2, two subjects discontinued treatment because of an AE: one for moderate hemorrhoids after receiving dabigatran etexilate alone (considered not to be drug related), and one for moderate hematuria while receiving clopidogrel +dabigatran etexilate. A third subject withdrew his consent after receiving clopidogrel alone. In part 3, one subject withdrew his consent after receiving clopidogrel alone.

Vital signs, ECG, and safety laboratory assessments did not indicate any relevant, consistent, or treatment-related untoward reactions. Global clinical tolerability was good in all subjects, except in one subject during treatment with clopidogrel+dabigatran. This subject, who reported global tolerability as "not satisfactory," discontinued the trial because of an AE (moderate hematuria).

\section{Discussion}

Given the different mechanisms of action of anticoagulants and antiplatelet drugs, combining these agents has the potential to reduce thromboembolic events and their consequences, although with the likelihood of an increased risk of bleeding [1, 2]. Furthermore, if any drug-drug interactions between the selected anticoagulant and antiplatelet drugs are present, the bleeding risk could be substantially increased. Our study shows that after multiple dosing of clopidogrel $75 \mathrm{mg}$ qd (preceded by a loading dose of $300 \mathrm{mg}$ ) plus dabigatran etexilate $150 \mathrm{mg}$ bid, exposure to free and total (free and glucuronide-conjugated) dabigatran remained essentially unchanged compared with 
Table 6 Parts 2 and 3. Means (original scale) and differences in inhibition of ADP-induced platelet aggregation by clopidogrel in combination with dabigatran etexilate $(\mathrm{DE})$ and alone

\begin{tabular}{|c|c|c|c|c|c|}
\hline $\begin{array}{l}\text { Parameter } \\
\text { Part } 2\end{array}$ & $\begin{array}{l}\text { Clopidogrel } 75 \mathrm{mg} \mathrm{qd} \\
\text { + DE } 150 \mathrm{mg} \text { bid } \\
\text { Test treatment }\end{array}$ & $\begin{array}{l}\text { Clopidogrel } 75 \mathrm{mg} \text { qd } \\
\text { Reference treatment }\end{array}$ & $\begin{array}{c}\text { Difference } \\
\text { Test - reference }\end{array}$ & $90 \% \mathrm{Cl}$ & $\begin{array}{l}\text { Intra- } \\
\text { individual } \\
\text { gCV \% }\end{array}$ \\
\hline & Mean & Mean & & & \\
\hline $\begin{array}{l}\text { AUEC } C_{\mid P A}, \tau, s s \\
\% \cdot h\end{array}$ & 456 & 496 & $-39.7(-8.0 \%)$ & -96.5 to 17.2 & 20.3 \\
\hline$E_{\max , s s}$ & 55.1 & 58.8 & $-3.71(-6.3 \%)$ & -12.9 to 5.49 & 29.0 \\
\hline $\begin{array}{l}\text { Parameter } \\
\text { Part } 3\end{array}$ & $\begin{array}{c}\text { Clopidogrel } 600 \mathrm{mg}+ \\
\text { DE } 150 \mathrm{mg} \text { bid } \\
\text { Test treatment }\end{array}$ & $\begin{array}{l}\text { Clopidogrel } 600 \mathrm{mg} \\
\text { Reference treatment }\end{array}$ & $\begin{array}{c}\text { Difference } \\
\text { Test - treatment }\end{array}$ & $90 \% \mathrm{Cl}$ & $\begin{array}{l}\text { Intra- } \\
\text { individual } \\
\text { gCV \% }\end{array}$ \\
\hline & Mean & Mean & & & \\
\hline AUEC $_{0-24}, \% \cdot h$ & 1179 & 1264 & $-84.6(-6.7 \%)$ & -293 to 124 & 21.6 \\
\hline$E_{\max }$ & 66.8 & 66.0 & $0.826(1.3 \%)$ & -10.8 to 12.5 & 23.4 \\
\hline
\end{tabular}

$\overline{A U E C}_{0-24}$ Area under the effect curve of inhibition of platelet aggregation after the loading dose of $600 \mathrm{mg}$ clopidogrel from drug administration until $24 \mathrm{~h}$ thereafter (at steady state), $A U E C_{\tau, s s}$ area under the effect curve of inhibition of platelet aggregation (at steady state), bid twice daily, $C I$ confidence interval, $E_{\max }$ maximum percentage change (compared with baseline) in ADP-induced platelet aggregation of clopidogrel (E $\mathrm{E}_{\text {max,ss}}$, at steady state), $q d$ once daily

dabigatran etexilate monotherapy. Concomitant intake of clopidogrel did not affect dabigatran glucuronidation, and no or only minimal effects of dabigatran on the PK of clopidogrel or its inactive metabolite (SR26334), or on the inhibition of platelet aggregation induced by the active metabolite of clopidogrel were observed.

Clopidogrel in this therapeutic regimen (a $300 \mathrm{mg}$ loading dose followed by $75 \mathrm{mg} \mathrm{qd}$ ) had only minimal effects on the coagulation markers aPTT, ECT, and TT; the latter two are closely related to thrombin inhibition. Accordingly, the effect of dabigatran and the PK/PD relationship were essentially the same when dabigatran etexilate was given with or without concomitant clopidogrel. A high loading dose of clopidogrel $600 \mathrm{mg}$ also had no effect on the thrombin-related coagulation markers.

Clopidogrel inhibits the platelet-surface ADP receptor $\mathrm{P} 2 \mathrm{Y}_{12}$, decreasing platelet activation and aggregation processes [10]. Dabigatran did not influence the inhibition of ADP-dependent platelet aggregation by clopidogrel. Furthermore, dabigatran alone did not prolong CBT, a measure to assess platelet-driven coagulation [22, 23]. Maximum CBT was clearly prolonged by any treatment regimen that included clopidogrel compared with dabigatran monotherapy. However, there was no difference in CBT between clopidogrel given alone or in combination with dabigatran etexilate. In atrial fibrillation patients, however, from the RE-LY trial, concomitant intake of clopidogrel and dabigatran etexilate led to an increased rate of major and any bleeding [24]. In a phase I trial, the first oral direct thrombin inhibitor, ximelagatran, in combination with acetylsalicylic acid (ASA) further prolonged CBT by about $40 \%$ compared with ASA alone [25]. Bleeding time with the combination rivaroxaban and clopidogrel was significantly prolonged in four subjects, compared with either drug alone, which increased the overall least square means to $3.77(90 \%$ CI 2.82-4.73) times baseline with the combination, compared with 1.13 times baseline $(90 \% \mathrm{CI}$ $0.17-2.09)$ with rivaroxaban and 1.96 times baseline $(90 \% \mathrm{CI}$ $0.10-2.91$ ) with clopidogrel [26]. The results with dabigatran observed in this study seem to some extent different from previously observed data with other oral anticoagulants such as ximelagatran and rivaroxaban.

A high loading dose of clopidogrel $600 \mathrm{mg}$ was associated with an increase (32\%) in the bioavailability of dabigatran. Exposure to clopidogrel and SR26334 was similar when clopidogrel was administered alone or with multiple doses of dabigatran etexilate $150 \mathrm{mg}$ bid. The efflux transporter P-gp in the gastrointestinal tract can directly limit oral drug absorption [27, 28]; dabigatran etexilate, but not dabigatran, is a substrate for P-gp [8, 29]. Concomitant administration of strong P-gp inhibitors, including quinidine, amiodarone, verapamil, ketoconazole, and clarithromycin, raises dabigatran serum concentrations [8, 29, 30]. Clopidogrel also has been shown to be a substrate of P-gp [9]. Clopidogrel absorption, and thereby formation of its active metabolite, is diminished by P-gp-mediated efflux [9]. A high 
loading dose of clopidogrel (either 300 or $600 \mathrm{mg}$ ) may have the potential to competitively inhibit intestinal P-gp, causing an increase in dabigatran bioavailability. A high, $600 \mathrm{mg}$, loading dose of clopidogrel is widely used in clinical practice, especially in acute settings, to reduce intra-individual variability and enhance responsiveness [14-17]. However, this clopidogrel loading dose is given for only 1 day. This transient increase in dabigatran exposure for a single day by about $30 \%$ should be taken into consideration particularly in vulnerable patients at high risk of bleeding. However, it remains to be determined whether this effect, which is only observed for the first day of a combination treatment, is likely to have any clinical impact at all.

Unlike dabigatran, which is not metabolized via CYP isoenzymes, clopidogrel requires hepatic CYP metabolic activation to produce its pharmacologically active metabolite $[10,11]$. In addition to CYP3A4, CYP2C19 is particularly important relative to other CYP enzymes in the formation of the active metabolite of clopidogrel $[12,13]$. As neither dabigatran nor its prodrug is an inhibitor of any CYP, dabigatran comedication should not diminish the therapeutic efficiency of clopidogrel. In accordance with published data [21], subjects carrying the ultrarapid metabolizer allele $C Y P 2 C 19^{*} 17$ had a trend to more efficient inhibition of ADP-dependent platelet aggregation. However, in general the CYP2C19 genotype did not influence PK and PD after comedication with dabigatran etexilate.

Concomitant administration of dabigatran and clopidogrel did not reveal any unexpected safety findings in the healthy male subjects included in this clinical trial. All AEs observed were of mild to moderate intensity, none were serious, and all had resolved by the end of the study, with the exception of ongoing hemorrhoids in one subject. Reported AEs, including hematoma, hematuria, and rash, were consistent with the labelling of dabigatran and clopidogrel and were not unexpected, even in healthy volunteers. Three bleeding events were potentially related to drug effects on coagulation: two cases of moderate hematoma (one subject given clopidogrel alone; one subject receiving clopidogrel+dabigatran) and one case of moderate hematuria (subject received clopidogrel+dabigatran and subsequently discontinued treatment). However, there was no correlation between the individuals' PK data and these bleeding events. Although these results are not conclusive, dabigatran etexilate in this study did not seem to cause any safety issues, whether given alone or in combination with clopidogrel.

The study was designed as a phase I study in healthy volunteers and aimed to clarify any PK/PD interaction between clopidogrel and dabigatran etexilate. This type of study does not allow any conclusions to be drawn with respect to the clinical effects of long-term use of the combination in atrial fibrillation patients. However, dabigatran etexilate was administered at the therapeutic dose of $150 \mathrm{mg}$ bid, and clopidogrel was administered at dosages used in clinical practice. The designs of the pilot and two main parts of the study were purposefully chosen. The pilot study (part 1) had a fixed-sequence design (multiple doses of dabigatran $150 \mathrm{mg}$ followed by a single dose of clopidogrel) for safety reasons. In the main study, the crossover design was used as is usually done for drug-drug interaction studies due to its efficiency, i.e., the comparison between treatments based on a comparison within subjects rather than between subjects (part 2). A washout period of 14 days was considered to be sufficient to separate the three treatments, based on the half-life of dabigatran $(8-10 \mathrm{~h}$ and $14-17 \mathrm{~h}$ with single- and multiple-dose administrations, respectively [7]). The combination of dabigatran with a high clopidogrel dose $(600 \mathrm{mg}$ ) warranted a fixed-sequence design (one drug alone followed by the combination) for safety reasons (part 3).

In summary, steady-state dosing of clopidogrel $75 \mathrm{mg}$ qd (following a $300 \mathrm{mg}$ loading dose) and dabigatran etexilate $150 \mathrm{mg}$ bid demonstrated no effect on dabigatran PK or PD, or its PK/PD relationships (aPTT, ECT, or TT). Similarly, the PK of clopidogrel and its PD effects on the inhibition of platelet aggregation were unchanged by chronic administration of dabigatran etexilate. There may be modest but very transient effects on dabigatran PK (30-35\% increase in AUC) when a loading dose of clopidogrel (300 or $600 \mathrm{mg}$ ) is administered, with no impact on the PK or PD of clopidogrel.

Acknowledgments Editorial support was provided by Elena Garonna of PAREXEL and was funded by Boehringer Ingelheim International $\mathrm{GmbH}$. Bioanalytics were performed by Dietmar Ganser, Boehringer Ingelheim Pharma GmbH \& Co. KG.

Conflict of interest The study was financially supported by Boehringer Ingelheim. S.H., R.S., C.S., J.F., and H.F. are current employees at Boehringer Ingelheim Pharma GmbH \& Co. KG.

Open Access This article is distributed under the terms of the Creative Commons Attribution License which permits any use, distribution, and reproduction in any medium, provided the original author(s) and the source are credited.

\section{References}

1. Buresly K, Eisenberg MJ, Zhang X, Pilote L (2005) Bleeding complications associated with combinations of aspirin, thienopyridine derivatives, and warfarin in elderly patients following acute myocardial infarction. Arch Intern Med 165:784-789

2. Johnson SG, Witt DM, Eddy TR, Delate T (2007) Warfarin and antiplatelet combination use among commercially insured patients enrolled in an anticoagulation management service. Chest 131:1500 1507

3. Hauel NH, Nar H, Priepke H, Ries U, Stassen JM, Wienen W (2002) Structure-based design of novel potent nonpeptide thrombin inhibitors. J Med Chem 45:1757-1766

4. Wienen W, Stassen JM, Priepke H, Ries UJ, Hauel N (2007) Invitro profile and ex-vivo anticoagulant activity of the direct 
thrombin inhibitor dabigatran and its orally active prodrug, dabigatran etexilate. Thromb Haemost 98:155-162

5. Weitz JI (2007) Factor Xa or thrombin: is thrombin a better target? J Thromb Haemost 5(Suppl 1):65-67

6. Blech S, Ebner T, Ludwig-Schwellinger E, Stangier J, Roth W (2008) The metabolism and disposition of the oral direct thrombin inhibitor, dabigatran, in humans. Drug Metab Dispos 36:386-399

7. Stangier J, Rathgen K, Stahle H, Gansser D, Roth W (2007) The pharmacokinetics, pharmacodynamics and tolerability of dabigatran etexilate, a new oral direct thrombin inhibitor, in healthy male subjects. Br J Clin Pharmacol 64:292-303

8. European Medicines Agency (2011) Pradaxa: summary of product characteristics. http://www.ema.europa.eu/docs/en_GB/document library/EPAR_-_Product_Information/human/000829/ WC500041059.pdf. Accessed September 12, 2011

9. Taubert D, Von Beckerath N, Grimberg G, Lazar A, Jung N, Goeser T, Kastrati A, Schomig A, Schomig E (2006) Impact of P-glycoprotein on clopidogrel absorption. Clin Pharmacol Ther 80:486-501

10. Sikka P, Bindra VK (2010) Newer antithrombotic drugs. Indian J Crit Care Med 14:188-195

11. Savi P, Herbert JM, Pflieger AM, Dol F, Delebassee D, Combalbert J, Defreyn G, Maffrand JP (1992) Importance of hepatic metabolism in the antiaggregating activity of the thienopyridine clopidogrel. Biochem Pharmacol 44:527-532

12. Steinhubl SR (2010) Genotyping, clopidogrel metabolism, and the search for the therapeutic window of thienopyridines. Circulation $121: 481-483$

13. Kazui M, Nishiya Y, Ishizuka T, Hagihara K, Farid NA, Okazaki O, Ikeda T, Kurihara A (2010) Identification of the human cytochrome P450 enzymes involved in the two oxidative steps in the bioactivation of clopidogrel to its pharmacologically active metabolite. Drug Metab Dispos 38:92-99

14. L'Allier PL, Ducrocq G, Pranno N, Noble S, Ibrahim R, Gregoire JC, Azzari F, Nozza A, Berry C, Doucet S, Labarthe B, Theroux P, Tardif JC (2008) Clopidogrel 600-mg double loading dose achieves stronger platelet inhibition than conventional regimens: results from the PREPAIR randomized study. J Am Coll Cardiol 51:1066-1072

15. Patti G, Colonna G, Pasceri V, Pepe LL, Montinaro A, Di SG (2005) Randomized trial of high loading dose of clopidogrel for reduction of periprocedural myocardial infarction in patients undergoing coronary intervention: results from the ARMYDA-2 (Antiplatelet therapy for Reduction of MYocardial Damage during Angioplasty) study. Circulation 111:2099-2106

16. Von Beckerath N, Pogatsa-Murray G, Schomig E, Kastrati A, Schomig A (2005) Absorption, metabolization, and antiplatelet effects of 300-, 600-, and 900-mg loading doses of clopidogrel: results of the ISAR-CHOICE (Intracoronary Stenting and Antithrombotic Regimen: Choose Between 3 High Oral Doses for Immediate Clopidogrel Effect) Trial. Circulation 112:2946-2950

17. Angiolillo DJ, Fernandez-Ortiz A, Bernardo E, Ramirez C, Sabate M, Banuelos C, Hernandez-Antolin R, Escaned J, Moreno R, Alfonso F, Macaya C (2004) High clopidogrel loading dose during coronary stenting: effects on drug response and interindividual variability. Eur Heart J 25:1903-1910

18. Shireman TI, Howard PA, Kresowik TF, Ellerbeck EF (2004) Combined anticoagulant-antiplatelet use and major bleeding events in elderly atrial fibrillation patients. Stroke 35:23622367

19. Hurbin F, Boulenc X, Daskalakis N, Farenc C, Taylor T, Bonneau D, Lacreta F, Cheng S, Sultan E (2011) Clopidogrel pharmacodynamics and pharmacokinetics in the fed and fasted state: a randomized crossover study of healthy men. J Clin Pharmacol. doi:10.1177/0091270011419852

20. Elashoff J (2005) NQuery advisor version 6.0 user's guide. Statistical Solutions, Cork

21. Sibbing D, Koch W, Gebhard D, Schuster T, Braun S, Stegherr J, Morath T, Schomig A, Von Beckerath N, Kastrati A (2010) Cytochrome 2 C19*17 allelic variant, platelet aggregation, bleeding events, and stent thrombosis in clopidogrel-treated patients with coronary stent placement. Circulation 121:512-518

22. Sutor AH, Bowie EJ, Owen CA Jr (1971) Effect of aspirin, sodium salicylate, and acetaminophen on bleeding. Mayo Clin Proc 46:178-181

23. Weston MJ, Rubin MH, Langley PG, Westaby S, Williams R (1977) Effects of sulphinpyrazone and dipyridamole on capillary bleeding time in man. Thromb Res 10:833-840

24. Eikelboom JW, Wallentin L, Connolly SJ, Ezekowitz M, Healey JS, Oldgren J, Yang S, Alings M, Kaatz S, Hohnloser SH, Diener HC, Franzosi MG, Huber K, Reilly P, Varrone J, Yusuf S (2011) Risk of bleeding with 2 doses of dabigatran compared with warfarin in older and younger patients with atrial fibrillation: an analysis of the randomized evaluation of long-term anticoagulant therapy (RE-LY) trial. Circulation 123:2363-2372

25. Wahlander K, Eriksson-Lepkowska M, Nystrom P, Eriksson UG, Sarich TC, Badimon JJ, Kalies I, Elg M, Bylock A (2006) Antithrombotic effects of ximelagatran plus acetylsalicylic acid (ASA) and clopidogrel plus ASA in a human ex vivo arterial thrombosis model. Thromb Haemost 95:447453

26. Kubitza D, Becka M, Mueck W, Zuehlsdorf M (2007) Coadministration of rivaroxaban - a novel, oral, direct factor Xa inhibitor - and clopidogrel in healthy subjects [abstract]. Eur Heart J 28 (CD)(Suppl):189. Abstr P1272

27. Lin JH (2003) Drug-drug interaction mediated by inhibition and induction of P-glycoprotein. Adv Drug Deliv Rev 55:53-81

28. Lin JH, Yamazaki M (2003) Role of P-glycoprotein in pharmacokinetics: clinical implications. Clin Pharmacokinet 42:59-98

29. Stangier J, Clemens A (2009) Pharmacology, pharmacokinetics, and pharmacodynamics of dabigatran etexilate, an oral direct thrombin inhibitor. Clin Appl Thromb Hemost 15(Suppl 1):9S$16 \mathrm{~S}$

30. Härtter S, Sennewald R, Rathgen K, Nehmiz G, Reilly P (2011) Increase in the oral bioavailability of dabigatran etexilate (Pradaxa ${ }^{\circledR}$ ) after co-medication with verapamil. Presented at the 112th Meeting of the American Society for Clinical Pharmacology and Therapeutics (ASCPT), Dallas, TX, USA, 2-5 March 2011 